\title{
Optimization of Turning Parameters of Cryogenic Soaked AZ91 Magnesium Alloy using TOPSIS coupled Taguchi Technique
}

\author{
Gunasekaran. $\mathrm{K}^{1}$, Pradeep Kumar. $\mathrm{G}^{2}$, Thanigaivelan. $\mathrm{R}^{1,{ }^{*}}$, Arunachalam. $\mathrm{R}^{3}$ and Shanmugam $\mathrm{V}^{4}$ \\ ${ }^{1}$ Department of Mechanical Engineering, Muthayammal Engineering College (Autonomous), Rasipuram -637408, India \\ ${ }^{2}$ Department of Mechanical Engineering, AVS college of Technology, Salem 636003. India \\ ${ }^{3}$ Department of Mechanical and Industrial Engineering, College of Engineering, Sultan Qaboos University, Oman \\ ${ }^{4}$ Department of Mechanical Engineering, Mahendra Engineering College (Autonomous), Mallasamudram -637503, India
}

\begin{abstract}
Corresponding Author Email: tvelan10@gmail.com
ABSTRACT

Magnesium alloys is a lightweight material establishing scope in various fields such as aerospace and automobile. Moreover, magnesium alloys are also considered as a hydrogen storage materials. In order to understand the machining behaviour of magnesium alloy a detail research is planned. In this research the turning experiments are conducted on AZ91 magnesium alloy using the L9 orthogonal array (OA) experimental design. Technique for Order of Preference by Similarity to Ideal Solution (TOPSIS) coupled with Taguchi and Analysis of Variance (ANOVA) methods are used to analysis the experiments. The influence of cryogenic soaking duration, feed, speed and depth of cut on cutting temperature, surface roughness and cutting force were studied. Based on the TOPSIS analysis the optimal combination for the better response is cryogenic soaking time of $30 \mathrm{~min}$, speed of $500 \mathrm{rpm}$, feed of $40 \mathrm{~mm} / \mathrm{min}$ and depth of cut of $0.3 \mathrm{~mm}$. As per $F$ value the depth of cut shows the 0.4822 and next best factors are cutting speed and feed rate. The chip analysis reveals that the cryogenic soaking duration level of 60 min is found to reduce the self-ignited chips.
\end{abstract}

Keywords: Magnesium alloys, Cryogenic soaking Duration, TOPSIS, Cutting temperature, Surface roughness, Cutting force Received: October-10-2020, Accepted: January-15-2021, https://doi.org/10.14447/jnmes.v24i1.a09

\section{NOMENCLATURE}

$\begin{array}{ll}\text { CD } & \text { Cryogenic duration in minutes } \\ \text { v } & \text { Speed, } \mathrm{rpm}^{1} \\ \mathrm{f} & \text { feed, } \mathrm{mm} / \mathrm{min} \\ \mathrm{d} & \text { depth of cut, } \mathrm{mm} \\ \text { DoF } & \text { Degrees of Freedom }\end{array}$

\section{INTRODUCTION}

Magnesium alloys exhibits an excellent combination of mechanical properties, corrosion resistance, and cast ability. Among the magnesium alloys the most widely used commercial alloy is AZ91 which find applications in automobile, electronics, compact devices and biodegradable medical implants [1]. Magnesium with hydrogen form a nonmetallic hydride $\mathrm{MgH}_{2}$, and it has a relatively high hydrogen storage capacity of $7.6 \mathrm{wt}$. \%. Hence most of the researchers target magnesium alloy for developing hydrogen storage materials.Therefore machinability studies of magnesium alloys contribute extensively to use them in suitable applications. Viswanathan et al. (2020) investigated the cutting force, material removal rate, tool flank wear and surface roughness in turning of magnesium alloy with PVD coated carbide insert in dry conditions. They optimized the process parameters using hybrid Taguchi GRA together with PCA analysis. Based on the study the most significant parameter on the multiple performances is found to be the depth of cut. Danish et al (2019) investigated the influence of cryogenic machining of AZ31C magnesium alloy on surface integrity parameters. The cryogenic machining has improved the surface integrity, quality, corrosion resistance and reduces ignition risk. Carou et al. (2014) experimentally investigated turning of magnesium alloy with different machining conditions such as cutting speed, depth of cut and feed rate at dry machining with minimum quantity lubrication system. The statistical analysis indicates that the feed rate is the major factor for all the tests. Buldum et al. (2012) optimized the cutting forces and surface roughness for maximum material removal rate (MRR) using the combination of Grey relational analysis and Taguchi method. Based on the study the cutting depth is found to be a most influential factor for turning magnesium alloy. Abbas et al (2018) applied an artificial neural network to optimize the $\mathrm{CNC}$ turning parameters on minimal machining time and at prime machining costs. The finish-turning parameters estimated were cutting speed $=250 \mathrm{~m} / \mathrm{min}$, cutting depth $=1.0 \mathrm{~mm}$, and feed per revolution $=0.08 \mathrm{~mm} / \mathrm{rev}$. Guozhong Chai et al. (2010) studied the dry cutting properties on magnesium alloy AZ91D along with kentanium cutting tools. Results showed that the cutting depth was the primary influence factor on cutting force, after feed rate and cutting speed. Rubio et al. (2014) in their study compared two sustainable cooling systems (dry machining and minimum quantity lubrication (MQL) system) in intermittent turning of UNS M11917 magnesium pieces. They concluded that the feed rate is the most important source of surface roughness variability. Villeta et al (2011) investigated and optimized the effect of dry turning parameters on the surface finish of magnesium pieces by applying the Taguchi techniques and statistical tests. The study reveals that surface finish is influenced by the feed rate. Dinesh et al. (2015) have conducted turning experiments on ZK60 magnesium alloys under various cutting speed and feed rate. The Influence of liquid nitrogen during machining was investigated. The cryogenic cooling 

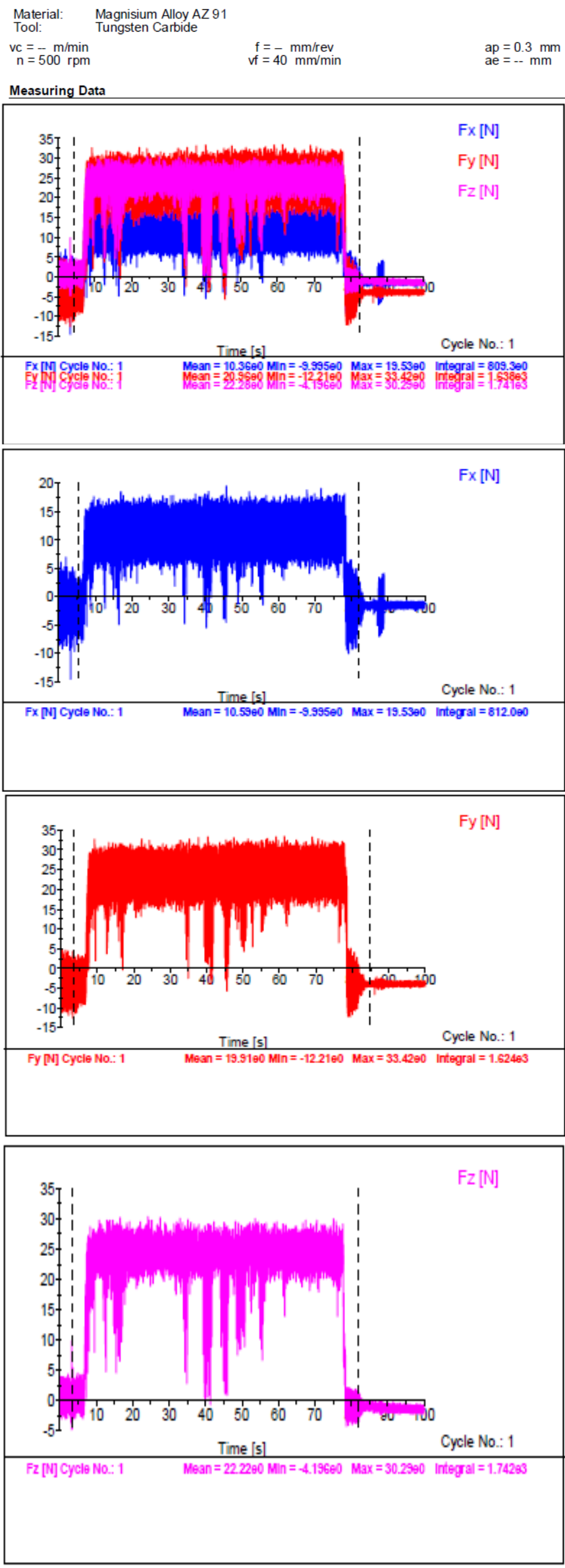

Figure.1.Cutting force generated at $30 \mathrm{~min}$ cryogenic treatment, speed $500 \mathrm{rpm}$,feed $40 \mathrm{~mm} / \mathrm{min}$ and depth of cut $0.3 \mathrm{~mm}$ over dry machining reduces the cutting temperature and cutting forces, improvement in surface finish and hardness were observed. Eker et al. (2014) compared the MQL turning performance with dry conditions by applying the orthogonal CNC cutting. They reveal that the turning with MQL supply is more effective because MQL provides the benefits mainly by reducing the cutting temperature, which also increases tool life. It is evident from the discussed literatures that turning of magnesium alloy with cryogenic treatment, dry machining, MQL and coated inserts on surface quality, cutting force, tool flank wear and MRR were preformed. In this research the magnesium alloy is treated to cryogenic condition for different hours and the temperature is reduced at the rate of $20^{\circ} \mathrm{C} / \mathrm{min}$ from room temperature. Liquid nitrogen is used for the cryogenic treatment. The treated specimen is subject to turning operation in Kirloskar variable speed and feed center lathe. The influence of time of cryogenic soaking, feed, speed and depth of cut on cutting temperature, surface roughness and cutting force were studied. L9 orthogonal array (OA) experimental design is used with four factors and three levels. A full factorial design will provide all possible combinations for a identified factors. Since most industrial experiments often use a major number of factors, a full factorial design results in a more number of experiments. In order to reduce the quantity of experiments, a small set from all the possibilities is selected. The method of selecting a limited number of experiments which produces the most information is designed by Taguchi This method uses a special set of arrays called OAs. The performance of the turning is analyzed using Technique for Order of Preference by Similarity to Ideal Solution (TOPSIS) coupled with Taguchi technique and Analysis of Variance (ANOVA).

\section{EXPERIMENTAL SETUP}

The magnesium alloy (AZ91) specimens are soaked in liquid nitrogen for different duration of time ie 30, 45 and 60 minutes respectively. The specimens are machined using uncoated tungsten carbide cutting tool inserts under dry condition. In the present study, optimization has been carried out using TOPSIS coupled with Taguchi technique. The experiments are planned using Taguchi's L ${ }_{9}$ OA that helps to reduce the number of experimental runs. Four control factors with three different levels are used for the experimentation. The factors such as cryogenic soaking duration (CD), speed (v), feed (f) and depth of cut (d) have been investigated on responses such as cutting temperature (Tc), surface roughness (R) and cutting force $(\mathrm{F})$. Also morphology of machined chips has been analyzed with cutting parameters. The turning operations are carried out in an all geared Kirloskar lathe machine.Three orthogonal cutting forces (Fx, $\mathrm{Fy}, \mathrm{Fz}$ ) acting on the cutting tool in the $\mathrm{X}, \mathrm{Y}$, and $\mathrm{Z}$ directions were measured by a three-component piezoelectric dynamometer under tool holder with the appropriate load amplifier. Figure 1 shows the cutting forces graphs and $\mathrm{X}$ axis shows the time of machining in seconds and Y-axis shows the cutting force in Newtons. The roughness measurement is performed using a stylus type surface roughness tester (Taylor Hobson, Sutronic 25). The cutting temperature was observed by non-contact IR Thermometer. 
Table 1. Design of experimental matrix with actual values of process parameters and codes ( $\mathrm{L}_{9} \mathrm{OA}$ )

\begin{tabular}{|c|c|c|c|c|c|c|c|c|}
\hline \multicolumn{5}{|c|}{ Actual } & \multicolumn{4}{|c|}{ Level } \\
\hline Run & CD (min) & V (rpm) & $\mathrm{F}(\mathrm{mm} / \mathrm{min})$ & D (mm) & CD (min) & V (rpm) & $\mathrm{F}(\mathrm{mm} / \mathrm{min})$ & D (mm) \\
\hline 01 & 30 & 500 & 40 & 0.3 & 1 & 1 & 1 & 1 \\
\hline 02 & 30 & 750 & 60 & 0.6 & 1 & 2 & 2 & 2 \\
\hline 03 & 30 & 1000 & 80 & 0.9 & 1 & 3 & 3 & 3 \\
\hline 04 & 45 & 500 & 60 & 0.9 & 2 & 1 & 2 & 3 \\
\hline 05 & 45 & 750 & 80 & 0.3 & 2 & 2 & 3 & 1 \\
\hline 06 & 45 & 1000 & 40 & 0.6 & 2 & 3 & 1 & 2 \\
\hline 07 & 60 & 500 & 80 & 0.6 & 3 & 1 & 3 & 2 \\
\hline 08 & 60 & 750 & 40 & 0.9 & 3 & 2 & 1 & 3 \\
\hline 09 & 60 & 1000 & 60 & 0.3 & 3 & 3 & 2 & 1 \\
\hline
\end{tabular}

The machining parameters with their different levels and codes are presented in the table 1 . Table 2 shows the process responses.

\section{OPTIMIZATION OF INDIVIDUAL PERFORMANCE CHARACTERISTICS}

The effect of cutting parameters on individual responses is obtained using $\mathrm{S} / \mathrm{N}$ ratio and ANOVA analysis. A loss function is the deviation between the experimental value and the desired value. The value of the loss function is transformed into a signal-to-noise $(\mathrm{S} / \mathrm{N})$ ratio. Usually, there are three categories of the performance characteristic in the analysis of the $\mathrm{S} / \mathrm{N}$ ratio, that is, the lower-the-better, the higher-the-better, and the nominal- thebetter. The $\mathrm{S} / \mathrm{N}$ ratio for each level of process parameters is computed based on the $\mathrm{S} / \mathrm{N}$ analysis [12].In this study, smaller-the-better characteristic is considered to obtain the optimal process parameter.Based on the orthogonal design, the $\mathrm{S} / \mathrm{N}$ ratio values were separated out at various levels to determine the influence of each parameter. The mean $\mathrm{S} / \mathrm{N}$ ratio values are provided in table 3 for individual cutting parameters at levels 1, 2 and 3.The table 3 depicts the ranks based upon the delta statistics on comparing the relative magnitude of effects.

Table 2 Effect of cryogenic treatment on process responses

\begin{tabular}{lllllll}
\hline Run & $\begin{array}{l}\mathbf{T}_{\mathbf{c}} \\
(\mathbf{C})\end{array}$ & $\begin{array}{c}\text { S/N Ratio } \\
\text { of Tc }\end{array}$ & $\begin{array}{c}\mathbf{R} \\
(\boldsymbol{\mu} \mathbf{m})\end{array}$ & $\begin{array}{c}\mathbf{S} / \mathbf{N} \text { Ratio } \\
\text { of R }\end{array}$ & $\mathbf{F}(\mathbf{N})$ & $\begin{array}{c}\text { S/N Ratio } \\
\text { of } \mathbf{F}\end{array}$ \\
\hline 01 & 36.10 & -31.15 & 6.138 & -15.76 & 30.29 & -29.62 \\
02 & 38.63 & -31.73 & 5.727 & -15.15 & 54.09 & -34.66 \\
03 & 42.85 & -32.63 & 4.893 & -13.79 & 79.05 & -37.95 \\
04 & 44.24 & -32.91 & 6.944 & -16.83 & 101.5 & -40.12 \\
05 & 43.67 & -32.80 & 5.238 & -14.38 & 45.32 & -33.12 \\
06 & 41.52 & -32.36 & 6.113 & -15.72 & 61.42 & -35.76 \\
07 & 42.30 & -32.52 & 9.486 & -19.54 & 90.79 & -39.24 \\
08 & 48.63 & -33.73 & 4.925 & -13.84 & 56.46 & -35.03 \\
09 & 43.03 & -32.67 & 6.025 & -15.59 & 27.39 & -28.75 \\
\hline
\end{tabular}

\subsection{Analysis of $\mathrm{S} / \mathrm{N}$ ratio for cutting temperature}

The mean $\mathrm{S} / \mathrm{N}$ ratio response table for cutting temperature is shown in Table 3 . The highest $\mathrm{S} / \mathrm{N}$ ratio is considered as a optimal level and based on the table 3 , the optimal parameter combination for cutting temperature are cryogenic duration at level 1 , speed at level 1 , feed at level 1 and depth of cut at level $1\left(C D_{1}-v_{1}-f_{1}-d_{1}\right)$. Moreover, based on the delta values from the response table that cryogenic soaking duration is a significant factor followed by depth of cut. Fig. 2 shows no self ignited chips and it is evident that deep cryogenic soaking avoids the need of lubrication at lower feed rate. Moreover the cryogenic soaking produces lower cutting temperature and the chip analysis shows that the cryogenic soaking duration level of $60 \mathrm{~min}$ is found to reduce the self ignited chips with few twisted chips.

Table 3. Response table of mean $\mathrm{S} / \mathrm{N}$ ratio for cutting temperature

\begin{tabular}{ccccc}
\hline Level & CD & v & f & d \\
\hline 1 & -31.84 & -32.20 & -32.42 & -32.21 \\
2 & -32.70 & -32.76 & -32.44 & -32.21 \\
3 & -32.98 & -32.56 & -32.66 & -33.10 \\
Delta & 1.14 & 0.56 & 0.24 & 0.89 \\
Rank & 1 & 3 & 4 & 2 \\
\hline \multicolumn{5}{r}{} \\
\hline
\end{tabular}

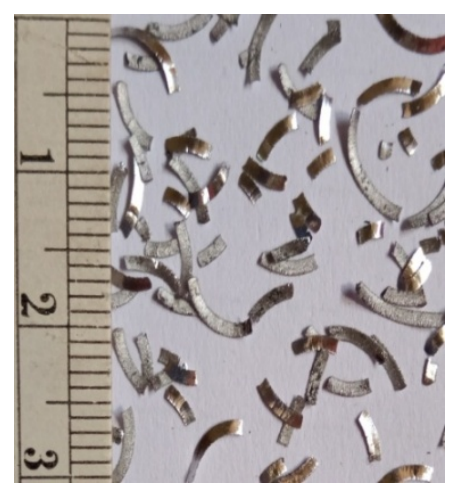

Figure 2. Twisted chips formed at $60 \mathrm{~min}$ cryogenic treatment, speed $750 \mathrm{rpm}$, feed $40 \mathrm{~mm} / \mathrm{min}$ and depth of cut $0.9 \mathrm{~mm}$.

\subsection{ANOVA for cutting temperature}

The ANOVA has been used to found the statistically significant input parameters affecting the output responses. This is obtained by separating the total variability of the $\mathrm{S} / \mathrm{N}$ ratios, which is calculated by the sum of squared deviations from the total mean of the $\mathrm{S} / \mathrm{N}$ ratio, along with the 
Gunasekaran K. et al. / J. New Mat. Electrochem. Systems

contributions by each of the cutting parameters and the error Additionally F-test is performed to judge the significant parameter affecting the responses. Larger the F-values shows more influence on the performance characteristics. The ANOVA for cutting temperature is shown in table 4. From the table it is clear that the cryogenic soaking duration has maximum contribution followed by the depth of cut. The cryogenic soaking duration shows $49.23 \%$ contribution among the four process variables and next highest contribution is depth of cut which shows $36.93 \%$. The cryogenic soaking of the specimen increases the tensile strength, hardness and Young's modulus of the material which attributes for smooth machining of the specimen. The increase in hardness improves the brittle property of the specimen and hence less force is required to turn the workpiece. This reduced force contributes lesser temperature at the cutting zone. It is also clear from the Fig. 2 that higher soaking duration contributes lower cutting temperature. Fig. 3 shows the short chips at lower cryogenic duration and depth of cut.

Table 4. ANOVA table for cutting temperature

\begin{tabular}{cccccc}
\hline Variables & DoF & SS & MS & F & \% contribution \\
\hline CD & 2 & 2.1020 & 1.0510 & 0.3903 & 49.23 \\
V & 2 & 0.4874 & 0.2437 & 0.0905 & 11.41 \\
f & 2 & 0.1030 & 0.0515 & 0.0191 & 2.41 \\
d & 2 & 1.5766 & 0.7883 & 0.2928 & 36.93 \\
Error & 1 & 2.6925 & 2.6925 & & 0.00 \\
Total & 9 & 6.9616 & 0.7735 & & 100 \\
\hline
\end{tabular}

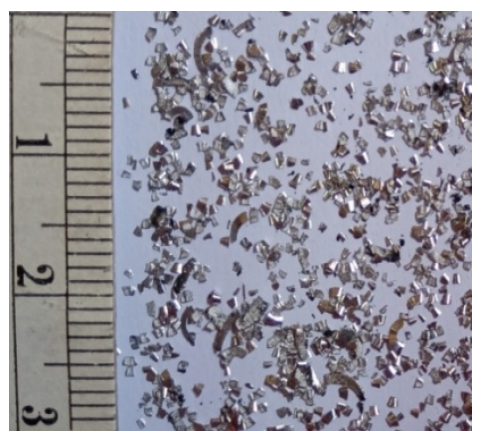

Figure 3. Shorter chips generated at $30 \mathrm{~min}$ cryogenic treatment, speed $500 \mathrm{rpm}$,feed $40 \mathrm{~mm} / \mathrm{min}$ and depth of cut $0.3 \mathrm{~mm}$

\subsection{Analysis of $\mathrm{S} / \mathrm{N}$ ratio for surface roughness}

The mean $\mathrm{S} / \mathrm{N}$ ratio of surface roughness is shown in table 5. The optimal parameters for the surface roughness are cryogenic soaking duration at level 1 , speed at level 2 , feed at level 1 and depth of cut at level 3. $\left(C D_{1}-v_{2}-f_{1}-d_{3}\right)$. Also the rank from response table shows that speed is a significant factor influences the surface roughness.
Table 5. Variation of $\mathrm{S} / \mathrm{N}$ ratio for surface roughness

\begin{tabular}{ccccc}
\hline Level & CD & $\mathbf{~}$ & $\mathbf{f}$ & $\mathbf{d}$ \\
\hline 1 & -14.90 & -17.38 & -15.11 & -15.25 \\
2 & -15.65 & -14.46 & -15.86 & -16.81 \\
3 & -16.33 & -15.04 & -15.91 & -14.82 \\
Delta & 1.43 & 2.91 & 0.79 & 1.98 \\
Rank & 3 & 1 & 4 & 2 \\
\hline \multicolumn{5}{l}{ Total Mean S/N ratio $=-15.62 \mathrm{~dB}$} \\
\hline
\end{tabular}

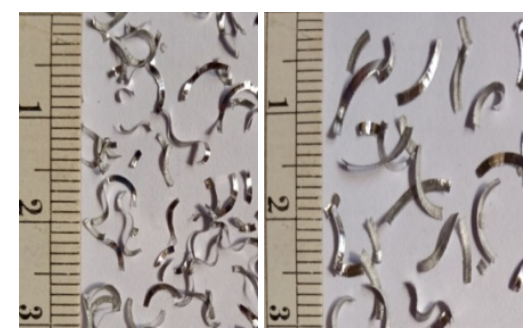

Figure 4. Fragmented chips generated at $500 \mathrm{rpm}$ and 80 $\mathrm{mm} / \mathrm{min}$

It is evident from the table 5 that increase in soaking duration increases the surface roughness. The increase in soaking duration improves the brittle property and during the material removal by fracture process the short chips generated evades the machining zone preventing the adherence of the chip on the specimen contributing for improved surface quality. Fig. 4 shows that the lower cutting speed $(500 \mathrm{rpm})$ causes fragmented and thinner chips due to large contact area on the rake face and small shear plane area. In contrast, chip thickness increases with increase in feed. During machining the material ahead of the tool rake is under intense compressive stress state and hence large volume of material becomes fully plastic which results in thick chip.

\subsection{ANOVA for surface roughness}

The ANOVA for surface roughness is shown in table 6 . From the table it is evident that the speed has maximum Fvalue and it contributes $56.96 \%$ among other parameters followed by the depth of cut. Based on ANOVA the speed is found to be a most dominant factor for surface roughness.

Table 6. Estimation of $\%$ contribution on surface roughness using ANOVA

\begin{tabular}{cccccc}
\hline Variables & DoF & SS & MS & F & \% contribution \\
\hline CD & 2 & 3.052 & 1.526 & 0.0823 & 12.15 \\
V & 2 & 14.300 & 7.150 & 0.3854 & 56.96 \\
f & 2 & 1.198 & 0.599 & 0.0323 & 4.77 \\
d & 2 & 6.553 & 3.276 & 0.1766 & 26.10 \\
Error & 1 & 18.551 & 18.551 & & 0.00 \\
Total & 9 & 43.656 & 4.850 & & 100 \\
\hline
\end{tabular}




\subsection{Analysis of $\mathrm{S} / \mathrm{N}$ Ratio for cutting force}

The mean $\mathrm{S} / \mathrm{N}$ ratio for cutting force is estimated and optimal result can be found out from the table 7 selecting highest levels of $\mathrm{S} / \mathrm{N}$ ratio values. The optimal combination for better cutting force are cryogenic soaking duration at level 1, speed at level 3, feed at level 1 and depth of cut at level 1 ie $\left(C D_{1}-v_{3}-f_{1}-d_{1}\right)$. It is evident in the response table 7 shows that the depth of cut is dominant factor for cutting force.

Table 7. Estimation of $\mathrm{S} / \mathrm{N}$ ratio for cutting force

\begin{tabular}{ccccc}
\hline Level & CD & v & f & d \\
\hline 1 & -34.08 & -36.33 & -33.48 & -30.50 \\
2 & -36.34 & -34.27 & -34.51 & -36.56 \\
3 & -34.34 & -34.16 & -36.77 & -37.71 \\
Delta & 2.26 & 2.17 & 3.30 & 7.21 \\
Rank & 3 & 4 & 2 & 1 \\
& Total Mean S/N ratio $=-34.92 \mathrm{~dB}$ & \\
\hline
\end{tabular}

\subsection{ANOVA for cutting force}

The table 8 shows the ANOVA table for cutting force. It is found that, as similar to response table, ANOVA shows the depth of cut is the most significant then other parameters. It has Highest $F$ value of 1.277 with $71.86 \%$ contribution. It is due to the formation of a built up edge which is a gathering of material beside the rake face that seizes to the tool tip, separating it from the chip. At higher depth of cut, the forces are lower owing to the thermal softening of the work material and also may be due to the effect of change in working rake angle resulted in the formation of built up edge.

Table 8: Estimation of significant process variable using ANOVA

\begin{tabular}{ccrrrr}
\hline Variables & DoF & \multicolumn{1}{c}{ SS } & \multicolumn{1}{c}{ MS } & \multicolumn{1}{c}{ F } & \% contribution \\
\hline CD & 2 & 9.159 & 4.579 & 0.1301 & 7.32 \\
V & 2 & 8.970 & 4.485 & 0.1274 & 7.16 \\
f & 2 & 17.073 & 8.536 & 0.2425 & 13.64 \\
d & 2 & 89.919 & 44.959 & 1.2771 & 71.86 \\
Error & 1 & 35.203 & 35.204 & & 0.00 \\
Total & 9 & 160.326 & 17.814 & & 100 \\
\hline
\end{tabular}

Based on the above analysis the depth of cut is found to be most significant factor which influence the cutting temperature, surface roughness and cutting force.

\section{MULTI-CRITERIA OPTIMIZATION USING TOPSIS METHOD}

TOPSIS is one of multi criteria decision making tool for solving complex problems. Taguchi technique is not suitable for multi response optimization. So multi objective optimization like TOPSIS method is used to overcome shortfalls of Taguchi's technique.

In this a multi-criteria optimization problem is converted into a single objective optimization problem using a combined approach of Taguchi's design and TOPSIS. The normalized matrix, weighted normalized decision matrix, separation of alternatives from positive and negative ideal solutions and preference values for TOPSIS obtained for each experimental run with the ranking order are presented here. The normalization of response is calculated by squaring the response values and dividing the same with the square root of the sum of the response values. The weighted normalized values is estimated by multiplying the weight of the response and the estimated normalized value. The relative closeness to the ideal solution value with highest rank is considered as the best value and performance measure for the process. The step-by-step procedure for TOPSIS is considered and estimated values are presented in the table as follows: [13-16]

The normalization values, weighted normalization values, are listed in table 9. Table 10 presents the estimation of separation measures and closeness coefficient values. In this study, equal priority is given to all the three responses. Based on the TOPSIS analysis the optimal combination for the better response is cryogenic soaking time of $30 \mathrm{~min}$, speed of $500 \mathrm{rpm}$, feed of $40 \mathrm{~mm} / \mathrm{min}$ and depth of cut of $0.3 \mathrm{~mm}$ $\left(C D_{1}-v_{1}-f_{1}-d_{1}\right)$.The ANOVA table 11 shows the $\mathrm{F}$ value and percentage contribution of the input parameters on the output responses. Based on the $F$ value the depth of cut shows the 0.4822 and hence it is considered as a significant factor that affects the output performance [17]. Next best factors are cutting speed and feed rate.

Table 9. Normalization and weighted values of TOPSIS method.

\begin{tabular}{ccccccc}
\hline \multirow{2}{*}{ Run } & \multicolumn{3}{c}{ Normalization Value } & \multicolumn{3}{c}{ Weighted normalized data } \\
& $\mathbf{T}_{\mathbf{c}}(\mathbf{C})$ & $\mathbf{R}(\boldsymbol{\mu} \mathbf{m})$ & $\mathbf{F}(\mathbf{N})$ & $\mathbf{T}_{\mathbf{c}}(\mathbf{C})$ & $\mathbf{R}(\boldsymbol{\mu m})$ & $\mathbf{F}(\mathbf{N})$ \\
\hline 1 & 0.2834 & 0.3244 & 0.1543 & 0.0944 & 0.1080 & 0.0514 \\
2 & 0.3033 & 0.3027 & 0.2755 & 0.1010 & 0.1008 & 0.0917 \\
3 & 0.3364 & 0.2586 & 0.4026 & 0.1120 & 0.0861 & 0.1341 \\
4 & 0.3473 & 0.3670 & 0.5169 & 0.1157 & 0.1222 & 0.1721 \\
5 & 0.3428 & 0.2768 & 0.2308 & 0.1142 & 0.0922 & 0.0769 \\
6 & 0.3260 & 0.3231 & 0.3128 & 0.1085 & 0.1076 & 0.1042 \\
7 & 0.3321 & 0.5014 & 0.4667 & 0.1106 & 0.1670 & 0.1554 \\
8 & 0.3818 & 0.2603 & 0.2875 & 0.1271 & 0.0867 & 0.0958 \\
9 & 0.3378 & 0.3184 & 0.1395 & 0.1125 & 0.1060 & 0.0465 \\
\hline
\end{tabular}

Table 10. Estimation of Rank

\begin{tabular}{cccc}
\hline Run & $\begin{array}{c}\text { Positive Matrix } \\
\text { S i+ }\end{array}$ & $\begin{array}{c}\text { Negative Matrix } \\
\text { S i- }\end{array}$ & Pi \\
\hline 1 & 0.0225 & 0.1383 & 0.8603 \\
2 & 0.0480 & 0.1073 & 0.6910 \\
3 & 0.0893 & 0.0906 & 0.5037 \\
4 & 0.1324 & 0.0462 & 0.2587 \\
5 & 0.0367 & 0.1218 & 0.7683 \\
6 & 0.0631 & 0.0921 & 0.5934 \\
7 & 0.1366 & 0.0235 & 0.1467 \\
8 & 0.0591 & 0.1108 & 0.6520 \\
9 & 0.0269 & 0.1404 & 0.8391 \\
\hline
\end{tabular}

Table 11. ANOVA table for closeness coefficient value

\begin{tabular}{cccccc}
\hline Variables & DoF & SS & MS & F & \% contribution \\
\hline CD & 2 & 0.0403 & 0.0202 & 0.0801 & 8.15 \\
V & 2 & 0.1326 & 0.0663 & 0.2634 & 26.81 \\
f & 2 & 0.0788 & 0.0394 & 0.1565 & 15.93 \\
d & 2 & 0.2428 & 0.1214 & 0.4822 & 49.09 \\
Error & 1 & 0.2517 & 0.2517 & & 0.0000 \\
Total & 9 & 0.7462 & 0.0829 & & 100 \\
\hline
\end{tabular}




\section{CONCLUSIONS}

Gunasekaran K. et al. / J. New Mat. Electrochem. Systems

The turning experiment on AZ91magenisum alloy is performed using $\mathrm{L}_{9} \mathrm{OA}$ experimental design. In the present study, optimization has been carried out using TOPSIS coupled with Taguchi technique. Based on the analysis the following conclusions are drawn.

1. The optimal combination for lesser cutting force are cryogenic soaking duration at level 1 , speed at level 3 , feed at level 1 and depth of cut at level 1. $\left(C D_{1}-v_{3}-f_{1}-d_{1}\right)$. Based on ANOVA the depth of cut is the most significant parameters affects the cutting force.

2. The optimal parameters for the surface roughness are cryogenic soaking duration at level 1 , speed at level 2 , feed at level 1 and depth of cut at level 3. $\left(C D_{1}-v_{2}-f_{1}-d_{3}\right)$. Based on ANOVA the speed has maximum F-value and it contributes $56.96 \%$ among other parameters followed by the depth of cut. 3. The optimal parameter combination for cutting temperature are cryogenic duration at level 1, speed at level 1 , feed at level 1 and depth of cut at level $1\left(C D_{1}-v_{1}-f_{1}-d_{1}\right)$. Cryogenic soaking duration has maximum contribution followed by the depth of cut.

4. Based on the TOPSIS analysis the optimal combination for the better response is cryogenic soaking time of $30 \mathrm{~min}$, speed of $500 \mathrm{rpm}$, feed of $40 \mathrm{~mm} / \mathrm{min}$ and depth of cut of $0.3 \mathrm{~mm}\left(C D_{1}-v_{1}-f_{1}-d_{1}\right)$. As per $\mathrm{F}$ value the depth of cut shows the 0.4822 and next best factors are cutting speed and feed rate.

5. Cryogenic soaking produces lower cutting temperature and the chip analysis shows that the cryogenic soaking duration level of $60 \mathrm{~min}$ is found to reduce the self-ignited chips.

\section{ACKNOWLEDGMENT}

This work is carried out at Karunya Institute of Technology and Sciences (Deemed to be University).

\section{REFERENCES}

[1] Polmear, I. J., Materials science and technology, 10(1), 1 (1994). https://doi.org/10.1179/mst.1994.10.1.1

[2] Viswanathan, R., Ramesh, S., Maniraj, S., \& Subburam, V., Measurement,159, 107800 (2020).
DOI: $10.1016 /$ j.measurement.2020.107800

[3] Mohd Danish, Turnad Lenggo Ginta, Ahmad Majdi Abdul Rani, Diego Carou, J.P.Davim, Saeed Rubaiee, Sami Ghazali, Procedia Manufacturing, 41, 476 (2019). https://doi.org/10.1016/j.promfg.2019.09.035

[4] Carou, D., Rubio, E. M., Lauro, C. H., \& Davim, J. P., Measurement, 56, 136 (2014).

DOI: $10.1016 /$ j.measurement.2014.06.020

[5] Buldum, B., Eşme, U., Kemal Külekci, M., Şik, A., \& Kazançoğlu, Y., Materials Testing, 54(11-12), 779 (2012). https://doi.org/10.3139/120.110392

[6] Abbas, A. T., Pimenov, D. Y., Erdakov, I. N., Taha, M. A., Soliman, M. S., \& El Rayes, M. M., Materials, 11(5), 808 (2018). DOI: 10.3390/ma1 1050808.

[7] Guo, X. H., Teng, L. J., Wang, W., \& Chen, T. T., In Advanced Materials Research, 102, 653 (2010). https://doi.org/10.1155/2018/9216314

[8] Rubio, E. M., Villeta, M., Carou, D., \& Saa, A., International journal of precision engineering and manufacturing, 15(5), 929 (2014)

[9] Villeta, M., Rubio, E. M., De Pipaón, J. S., \& Sebastián, M. A., Materials and Manufacturing Processes, 26(12), 1503 (2011). https://doi.org/10.1080/10426914.2010.544822

[10]Dinesh, S., Senthilkumar, V., Asokan, P., \& Arulkirubakaran, D., Materials \& design, 87, 1030 (2015). DOI: 10.1016/j.matdes.2015.08.099

[11]Eker, B., Ekici, B., Kurt, M., \& Bakır, B., Mechanics, 20(3), 310 (2014). DOI: 10.5755/j01.mech.20.3.4702

[12] Thanigaivelan, R., \& Arunachalam, R. M., Trans NAMRI/SME, 38, 253 (2010)

[13] Maniraj, S., \& Thanigaivelan, R., Transactions of the Indian Institute of Metals, 72(12), 3057 (2019).

[14] Rajan, N., Thanigaivelan, R., \& Muthurajan, K. G., Materials and technology, 53(6), 873 (2019).

[15] Yuvaraj, T., \& Suresh, P., Strojniski Vestnik/Journal of Mechanical Engineering, 65(10) (2019).

[16] Shanian, A., \& Savadogo, O., Journal of Power Sources, 159(2), 1095 (2006). https://doi.org/10.1016/j.jpowsour.2005.12.092.

[17] Kumar, G. P., Thanigaivelan, R., Arunachalam, R. M., \& Paramasivam, P., High Temperature Material Processes, 18(1-2), 27

(2014) 